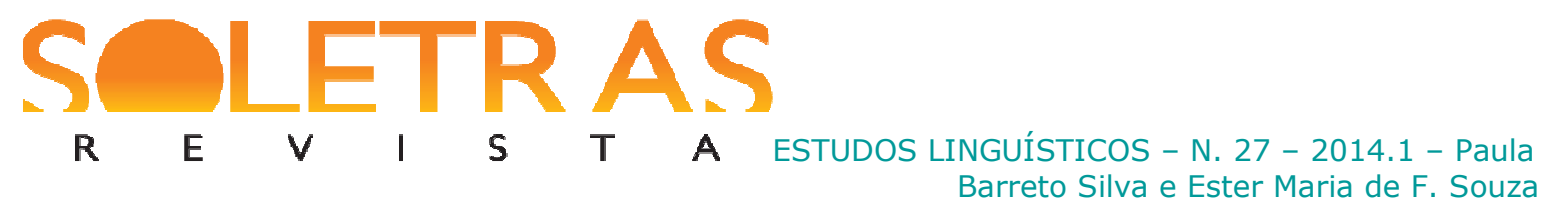

\title{
Educação linguística: o ensino de língua portuguesa no projeto Escrevendo o Futuro
}

\author{
Paula Barreto Silva ${ }^{1}$ \\ Universidade Estadual do Sudoeste da Bahia \\ Ester Maria de Figueiredo Souza ${ }^{2}$ \\ Universidade Estadual do Sudoeste da Bahia
}

\begin{abstract}
Resumo: O ensino de português tem sido agenciado nas políticas linguísticas brasileiras como um direito a ser ampliado e garantido a todos os cidadãos, tanto no âmbito da formação docente, para o domínio do conhecimento da língua e da didática de ensino, como para a educação linguística dos sujeitos aprendizes. Os índices oficiais de avaliação da educação básica revelam a necessidade de estarmos atentos à complexidade da educação em língua materna e nos impulsionam a promover reflexões sobre ações e medidas públicas de ensino de língua portuguesa desenvolvidas no país, no sentido de observar se essas procuram atender às demandas sociais. Busca-se, então, neste trabalho, extrair dos materiais da Olimpíada de Língua Portuguesa - OLP as concepções de ensino de língua para o território nacional, a partir do levantamento dos índices linguístico-discursivos sobre a reflexão e análise linguística presentes nos Cadernos do Professor. O programa em foco promove, entre alunos da rede pública, concursos bianuais de produção de textos escritos em quatro gêneros e se orienta por uma metodologia organizada em sequências didáticas. Os resultados apontam que a OLP se caracteriza como uma política de ensino que prioriza as normas de comportamento linguístico referentes aos gêneros textuais escritos e suas condições de produção e tende a se caracterizar como um veículo de planificação do ensino de língua no país.
\end{abstract}

Palavras-chave: Educação linguística. Gêneros textuais. Língua Portuguesa. Produção Escrita.

\section{Educação linguística à luz da concepção interacionista de linguagem}

Não há dúvida de que os saberes sobre a linguagem e seus recursos expressivos podem ser incorporados por qualquer pessoa em qualquer fase da vida, mas, quando se trata da reflexão sobre esses usos e da ampliação de domínios de linguagem para situações específicas de interação social, a intervenção formal e sistematizada no conhecimento que se tem sobre a língua é de fundamental importância. Essa intervenção no saber linguístico do indivíduo deve

\footnotetext{
${ }^{1}$ Mestre em Letras: Cultura, Educação e Linguagens. Pesquisadora do Grupo de Pesquisa "Linguagem e Educação - GPLED/CNPq". Atua em temáticas sobre políticas linguísticas e educação linguística.

${ }^{2}$ Doutora em Educação pela Universidade Federal da Bahia (2003). Professora titular da Universidade Estadual do Sudoeste da Bahia - UESB, no curso de Letras e no Programa de Pós-graduação em Letras. Líder do Grupo de Pesquisa "Linguagem e Educação - GPLED/CNPq". 
$\begin{array}{llllllll}\mathbf{R} & \mathbf{E} & \mathbf{V} & \mathbf{I} & \mathbf{S} & \mathbf{T} & \mathbf{A} & \text { ESTUdOS LINGUísticOS - N. } 27 \text { - } 2014.1 \text { - Paula }\end{array}$ Barreto Silva e Ester Maria de F. Souza

ter como princípio o respeito ao conhecimento linguístico que ele traz consigo e apresentar possibilidades de ampliação de sua competência comunicativa. Um trabalho que só pode ser realizado sob a orientação de um profissional que conceba o trabalho linguístico como uma ação de reflexão e formação humana. Isto porque se pressupõe que esse profissional esteja munido de conhecimentos teórico-metodológicos que tornam o acesso a determinados conhecimentos linguísticos mais eficiente e proveitoso. Assim, entendemos que adotar uma concepção de educação linguística e linguagem é extremamente necessário para o trabalho com a língua em instâncias formais, fato atestado por diversos autores e pesquisadores que se dedicam à reflexão sobre o ensino de língua portuguesa.

Vasconcelos (2009) compreende que é pressuposto da educação linguística um tratamento escolar cientificamente embasado. Segundo a autora, é necessário ao professor escolher uma vertente linguística para se aprofundar e, a partir de seus princípios e procedimentos, descrever a Língua Portuguesa. Corroborando com essa compreensão, Pessoa (2007) defende que o trabalho com educação linguística deve considerar como legítimos os usos das linguagens nas diversas situações sócio-comunicativas, sejam elas cotidianas e mais particulares, sejam aquelas institucionalizadas, públicas ou mais elaboradas. A pesquisadora sugere que o professor adote a concepção de língua e de linguagem defendida por Bakhtin para o trabalho com educação linguística em que a língua seja instrumento de interação entre os homens.

Sustentada nos estudos bakhtinianos, Souza (2009, p.104) também assume essa concepção para o trabalho com a linguagem, entendendo que na educação linguística formal: "o aluno apropria-se de conhecimentos e conceitos que ainda não domina, a fim de melhorar o seu desempenho linguístico." Um trabalho que não se resume ao ensino de regras e definições gramaticais, mas na incorporação de recursos linguísticos para o aprimoramento textual e discursivo de produções orais e escritas dos alunos, o que significa "[...] abdicar da "noção de neutralidade da linguagem e da compreensão dos conteúdos como imutáveis e fixos, como verdades já prontas".

Conduzir o ensino de Língua Portuguesa segundo a concepção interacionista, pressupõe, para o trabalho com educação linguística, atividades contínuas que extrapolem as instâncias formais de educação. O papel do professor na educação linguística formal se constitui, portanto, em apresentar ao aluno normas de comportamento linguístico, as quais ele possivelmente não teria acesso em situações informais e cotidianas de comunicação, para que 
$\begin{array}{llllllll}\mathbf{R} & \mathbf{E} & \mathbf{V} & \mathbf{I} & \mathbf{S} & \mathbf{T} & \mathbf{A} & \text { ESTUdOS LINGUísticOS - N. } 27 \text { - } 2014.1 \text { - Paula }\end{array}$ Barreto Silva e Ester Maria de F. Souza

ele se desenvolva e esteja, enquanto cidadão, habilitado para o exercício da linguagem nas diversas interações sociais.

Segundo Mendonça (2006, p. 206), “assumir determinada concepção de linguagem implica repensar o que é importante ensinar nas aulas de português e também como realizar esse ensino". A autora assume então a perspectiva sociointeracionista para o trabalho com análise linguística, defendendo que a seleção e o emprego de certos elementos e estratégias devem ser trabalhadas em consonância com as condições de produção dos textos de forma que isso possibilite uma análise sistemática e consciente sobre o que há de especial em cada gênero na sua relação com as práticas sociais de que fazem parte.

Santos e Oliveira (2012) destacam a existência de inúmeras iniciativas de ações do poder público, em parceria com outras instâncias, para a melhoria da educação em nosso país e pela inclusão educacional. Entretanto, considerando-se a complexidade da educação linguística, advertem que ainda há muito a fazer no campo das políticas públicas para que a noção de letramento impacte a vida social. As autoras consideram que a eficácia das políticas públicas depende do esforço da escola na sua reflexão sobre as relações entre as políticas de letramento e o modo como acontece a escolarização dos alunos, especialmente aqueles oriundos das camadas menos favorecidas, em favor de uma recontextualização de práticas e eventos relacionados à escrita nos espaços formais e informais de educação linguística. Isto porque, segundo as autoras, em muitas salas de aula, ainda predomina uma concepção de linguagem que desconsidera o seu caráter interacional, o que fragiliza o trabalho com as práticas de letramento escolares.

A mudança deve decorrer, portanto, das nossas opções políticas, teóricas e metodológicas no sentido de garantir uma concepção de leitura e de escrita diferenciada e inovadora para diminuir o fosso entre aquilo que os alunos fazem na escola e na vida cotidiana. Daí a importância dos projetos de educação linguística voltados para a ampliação da competência comunicativa dos alunos.

\section{Os gêneros como objeto e instrumento de ensino e o trabalho com sequências didáticas}

No domínio do ensino da produção de textos orais e escritos, Schneuwly e Dolz (2004) situam o gênero como meio de articulação entre as práticas sociais e os objetos escolares. Eles consideram o gênero "[...] um megainstrumento que fornece um suporte para a atividade, nas 
$\begin{array}{llllllll}\mathbf{R} & \mathbf{E} & \boldsymbol{V} & \mathbf{I} & \mathbf{S} & \mathbf{T} & \mathbf{A} & \text { ESTUdOS LINGUísticOS - N. } 27 \text { - } 2014.1 \text { - Paula }\end{array}$ Barreto Silva e Ester Maria de F. Souza

situações de comunicação, e uma referência para os aprendizes" (idem, p.64). Segundo os autores, os gêneros textuais são um termo de referência intermediário para a aprendizagem das práticas de linguagem que se materializam nas atividades dos aprendizes, mas que, no ambiente escolar, assumem uma realidade complexa.

A particularidade da situação escolar reside no seguinte fato que torna a realidade bastante complexa: há um desdobramento que se opera em que o gênero não é mais instrumento de comunicação somente, mas é, ao mesmo tempo, objeto de ensino-aprendizagem. $\mathrm{O}$ aluno encontra-se, necessariamente, num espaço do "como se", em que o gênero funda uma prática de linguagem que é, necessariamente, em parte, fictícia, uma vez que é instaurada com fins de aprendizagem (SCHNEUWLY; DOLZ, 2004, p. 65).

Para melhor compreensão desse aspecto do trabalho com gêneros na escola, Schneuwly e Dolz (2004) distinguem três maneiras de abordar o ensino de escrita e da fala, tendo como central o problema do gênero, como objeto, e as relações complexas que o ligam às práticas de referência. Num primeiro desdobramento, o gênero torna-se uma pura forma linguística, cujo domínio é objetivo, e transforma-se em forma de expressão do pensamento, da experiência ou da percepção. "Tratados" didaticamente, os gêneros parecem, então, desprovidos de qualquer relação com uma situação de comunicação autêntica e traduzem-se em produtos culturais da escola, cuja função é desenvolver e avaliar as capacidades de escrita dos alunos:

Os gêneros, sendo concebidos como forma de representação de diferentes realidades, têm uma forma que não depende de práticas sociais, mas da realidade mesma. Eles não são, então, formas, historicamente variáveis, de resolução de problemas comunicativos complexos que implicam uma referência a realidades em função de situações comunicativas mutáveis, mas modelos particularmente valorizados de representação do real (SCHNEUWLY; DOLZ, 2004, p. 66).

Outro desdobramento é o que considera a escola como lugar propício de comunicação e as situações escolares como ocasiões de produção/recepção de textos. Essa comunicação se realiza na classe - entre alunos - entre as classes na mesma escola e entre escolas:

A situação de comunicação é vista como geradora quase automática do gênero, que não é descrito, nem ensinado, mas aprendido pela prática de linguagem escolar, por meio dos parâmetros próprios à situação e das interações com os outros (SCHNEUWLY; DOLZ, 2004, p. 67).

O terceiro tipo de desdobramento, ao contrário do anterior, acontece pela negação da escola como lugar de específico de comunicação, como se os gêneros que funcionam nas práticas de linguagem pudessem entrar como tais na escola, numa continuidade absoluta entre o que é externo e interno à escola: 


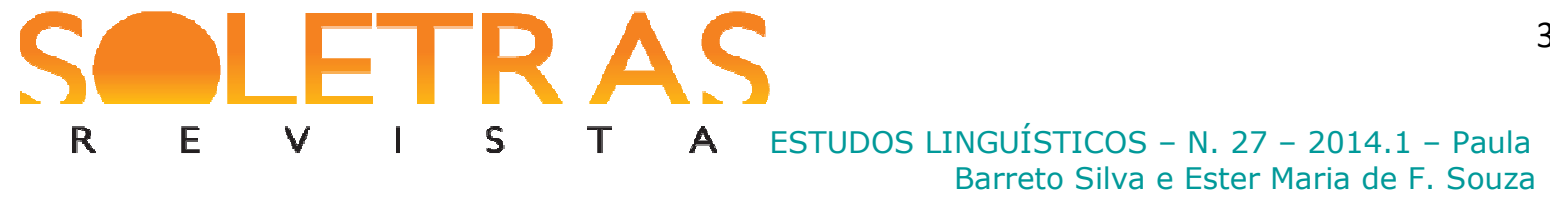

A representação do gênero na escola pode, então, ser descrita como segue: trata-se de levar o aluno ao domínio do gênero, exatamente como este funciona (realmente) nas práticas de linguagem de referência. Assim, essas últimas constituem, senão uma norma a atingir de imediato, ao menos um ideal que permanece como um alvo. [...] O que é visado é o domínio, o mais perfeito possível, do gênero correspondente à prática de linguagem para que, assim instrumentado, o aluno possa responder às exigências comunicativas com as quais ele é confrontado (SCHNEUWLY; DOLZ, 2004, p. 67-68).

Após analisar os pontos fracos e fortes de cada uma dessas tendências, os autores propõem uma revisão dos gêneros escolares através da tomada de consciência sobre o papel central desse objeto e instrumento de trabalho para o desenvolvimento da linguagem. Afirmam que é preciso levar em conta que: (a) a introdução do gênero na escola é o resultado de uma decisão didática que visa a objetivos precisos de aprendizagem e (b) que, na escola, ele passa a funcionar num outro lugar social, diferente daquele em que foi originado e sofre, forçosamente, uma transformação.

Schneuwly e Dolz (2004) consideram, portanto, que a introdução do gênero na escola faz dele, um gênero escolar e sugerem que essa variação pode ser descrita pela elaboração de modelos didáticos. Dolz et al. (2004, p.8) apresentam o procedimento "sequência didática" como uma maneira precisa de trabalhar em sala de aula. Essa se define por "um conjunto de atividades escolares organizadas, de maneira sistemática, em torno de um gênero textual oral ou escrito." O trabalho com a sequência didática visa à aquisição de condutas de linguagem num contexto de produção bem definido:

Uma sequência didática tem, precisamente, a finalidade de ajudar o aluno a dominar melhor um gênero de texto, permitindo-lhe, assim, escrever ou falar de uma maneira mais adequada numa dada situação de comunicação. $\mathrm{O}$ trabalho escolar será realizado, evidentemente, sobre gêneros que o aluno não domina ou o faz de maneira insuficiente; sobre aqueles dificilmente acessíveis, espontaneamente, pela maioria dos alunos; e sobre os gêneros públicos e não privados [...]. As sequências didáticas servem, portanto, para dar acesso aos alunos a práticas de linguagem novas ou dificilmente domináveis (DoLZ et al., 2004, p. 83).

Os autores esquematizam o procedimento da seguinte forma: 


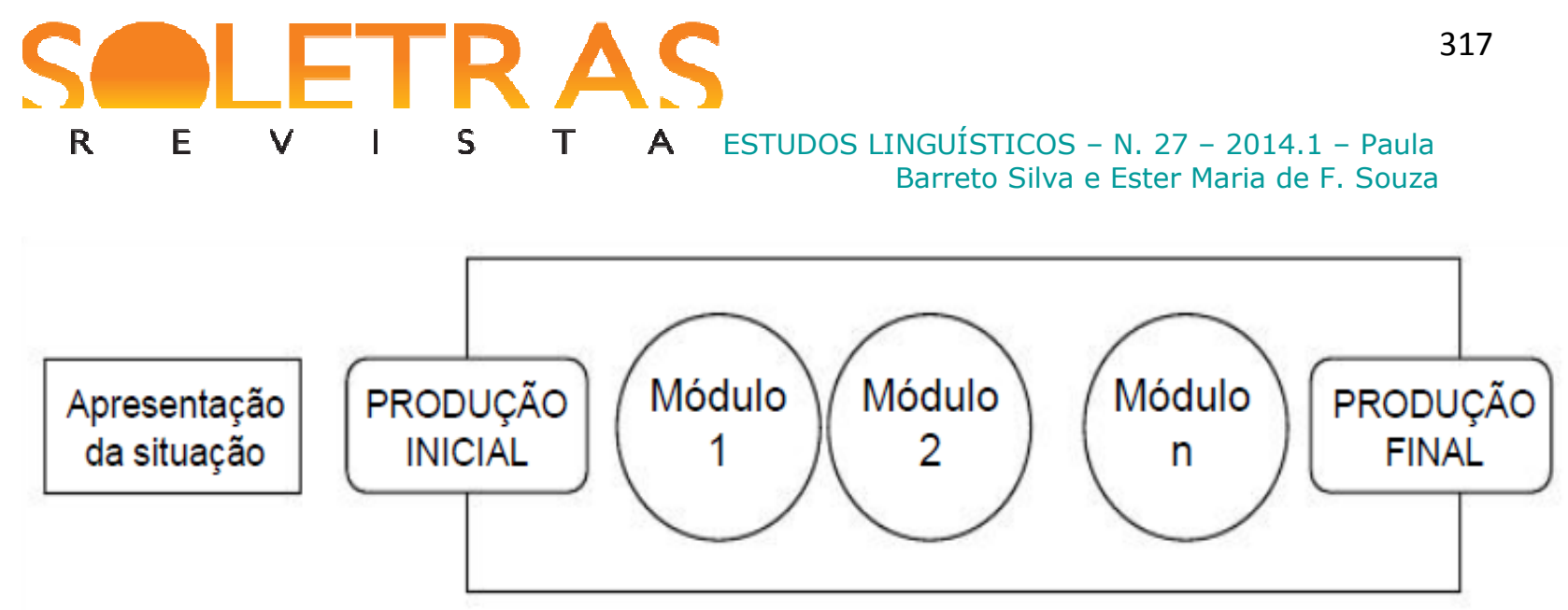

Figura 1 - Fonte Dolz et al. (2004, p. 83)

A proposta da sequência didática segue os procedimentos esquematizados acima. $\mathrm{Na}$ apresentação da situação, descreve-se a tarefa a ser realizada pelos alunos. Assim, eles elaboram a primeira produção que tem como finalidade revelar para os professores e para os próprios alunos as representações que têm dessa atividade. Essa etapa se constitui com uma avaliação formativa que permite circunscrever as capacidades que os alunos já dispõem e suas potencialidades, revelando para o professor o ponto preciso em que pode intervir melhor e o caminho que o aluno ainda tem a percorrer.

Nos módulos, são trabalhados, de maneira sistemática e aprofundada, os "problemas" que apareceram na primeira produção. Neles são realizadas várias atividades e vários exercícios para o domínio do gênero estudado. A produção final é o momento do aluno por em prática as noções e instrumentos elaborados separadamente nos módulos e permite uma avaliação do tipo somativo por parte do professor.

Dolz et al. (2004) empreendem algumas observações sobre o trabalho com a estruturação da língua e tecem comentários referentes à questões de gramática, sintaxe e ortografia no trabalho com as sequências didáticas. Eles destacam que as sequências têm por objetivo o aperfeiçoamento das práticas de escrita e produção oral a partir da aquisição de procedimentos e de práticas, mas admitem que o trabalho com as sequências não dá conta da totalidade do trabalho para levar a um melhor domínio da língua, devendo, portanto, apoiar-se em conhecimentos produzidos em outros domínios.

Eles explicam que, numa perspectiva textual, o trabalho com as sequências é complementar a outras abordagens. Segundo os autores, as sequências didáticas propõem numerosas atividades de organização, de manipulação e de análise das unidades linguísticas, cujo funcionamento só assume sentido pleno no nível textual.

Assim, o trabalho será centrado, por exemplo, nas marcas de organização características de um gênero, nas unidades que permitem designar uma mesma realidade ao longo de um texto, nos elementos de responsabilidade 
enunciativa e de modalização dos enunciados, no emprego de tempos verbais, na maneira como são utilizados e inseridos os discursos indiretos (DolZ et al., 2004, p. 96).

Os autores entendem que o domínio de uma sintaxe mais elaborada não está ligado a um gênero preciso. Para eles a compreensão sobre a organização da frase necessita de conhecimentos explícitos sobre o funcionamento da língua nesse nível e defendem a necessidade de se reservar tempo para um ensino específico de gramática em que se observe e manipule o funcionamento da língua.

\begin{abstract}
A bagagem que os alunos terão acumulado ao longo desses momentos de reflexão específica poderá ser reinvestida, com proveito, nas tarefas de escrita e revisão previstas nas sequências. Em contrapartida, as sequências permitirão contextualizar certos objetivos de aprendizagem e dar-lhes mais sentido (DOLZ et al., 2004, p. 97-98).
\end{abstract}

Os autores afirmam que as regras ortográficas são as mesmas em todos os textos, independentemente do gênero, e que os problemas encontrados nos textos dos alunos não estão exclusivamente relacionados à questão dos gêneros textuais. Entretanto, o trabalho com a produção escrita dá pistas essenciais ao professor para o trabalho com a ortografia e servem como base para a seleção de noções a serem estudadas em momentos específicos. Nas sequências didáticas, a revisão ou reescrita de textos produzidos constitui-se um de seus princípios, mas que deve ser tratado no final do percurso de produção textual, após o aperfeiçoamento de outros níveis textuais, quando se deve fazer uma revisão fina com o apoio de obras de referência como dicionários e manuais de ortografia, na versão final dos textos que serão lidos por outros.

\title{
A Olimpíada de Língua Portuguesa Escrevendo o Futuro
}

O programa Escrevendo o Futuro surgiu no ano de 2002, como uma ação de responsabilidade de organismos e empresas. $\mathrm{O}$ objetivo era estabelecer uma parceria entre as escolas de educação básica e o Ministério da Educação do Brasil, no intuito de contribuir para a melhoria do ensino de língua portuguesa e para a formação continuada de professores. Essa iniciativa da Fundação Itaú Social e do Centro de Estudos e Pesquisas em Educação, Cultura e Ação Comunitária (CENPEC) voltou-se inicialmente para alunos de $4^{\mathrm{a}}$ e $5^{\mathrm{a}}$ séries do Ensino Fundamental. O tema "O lugar onde vivo" era trabalhado em três gêneros textuais: Reportagem, Texto de Opinião e Poesia. 
$\begin{array}{llllllll}\mathbf{R} & \mathbf{E} & \mathbf{V} & \mathbf{I} & \mathbf{S} & \mathbf{T} & \mathbf{A} & \text { ESTUDOS LINGUÍSTICOS - N. } 27 \text { - } 2014.1 \text { - Paula }\end{array}$ Barreto Silva e Ester Maria de F. Souza

No ano de 2008, o programa se institucionalizou como Olimpíada de Língua Portuguesa Escrevendo o Futuro (OPL) a partir de uma parceria com o MEC, que encontrou no programa a metodologia adequada para realizar a Olimpíada. A partir disto, o programa foi incluído como uma ação do Plano de Desenvolvimento da Educação e ampliado para atender os anos restantes do Ensino Fundamental e o todo o Ensino Médio. Atualmente, o programa se constitui numa política pública de educação de abrangência nacional que toma os gêneros textuais como objeto e instrumento de ensino, fornecendo um material didático básico que traz um roteiro de sequências didáticas, organizadas em forma de oficinas, para direcionar o trabalho com a produção de textos escritos em sala de aula.

A melhoria da qualidade no ensino/aprendizagem da língua portuguesa é a principal meta do programa. Dentre seus principais objetivos, estão ainda: a busca por uma democratização dos usos da língua portuguesa, reduzindo o "iletrismo" e o fracasso escolar; o interesse em contribuir para melhorar o ensino da leitura e da escrita, fornecendo aos professores materiais e ferramentas; e também contribuir direta e indiretamente para a formação docente. O programa busca promover a aprendizagem da escrita dos seguintes gêneros: poema para $5^{\circ}$ e $6^{\circ}$ anos do Ensino Fundamental; memórias literárias para $7^{\circ}$ e $8^{\circ}$ anos do Ensino Fundamental; crônica para $9^{\circ}$ ano do Ensino Fundamental e $1^{\circ}$ ano do Ensino Médio; e artigo de opinião para $2^{\circ}$ e $3^{\circ}$ anos do Ensino Médio; tendo como central, para todos os gêneros, o tema "o lugar onde vivo".

A Olimpíada configura-se como um concurso de produção textual que funciona em duas fases: nos anos pares, acontece o processo do concurso; nos anos ímpares, ocorrem os cursos de formação de professores. A formação do professor acontece pelo acesso às publicações da revista $\mathrm{Na}$ Ponta do Lápis, pelos encontros regionais de formação e pelos cursos e conferências realizados na comunidade virtual.

A coordenação do Cenpec $^{3}$ em entrevista a Univesp TV, em 14 de setembro de 2012, declara que a Olimpíada tem um caráter diferente de outros concursos porque não tem a intenção de identificar talentos, mas antes de mobilizar os professores para ensinar língua portuguesa de uma maneira especial, diferente, em que a escrita seja um objeto real. Segundo ela, o programa tem por objetivo principal a formação e valorização do professor que experimenta um jeito diferente de trabalhar em sala de aula com o ensino da produção escrita de quatro gêneros diferentes. Para isso, o MEC distribui um material de base a todas as

\footnotetext{
${ }^{3}$ Declaração feita por Sônia Madi, coordenadora do Cenpec em entrevista à Univesp TV. Disponível em http://www.youtube.com/watch?v=aykXUbbYt5I\#t=221. Acesso em: 22 de dezembro de 2013. 
$\begin{array}{llllllll}\mathbf{R} & \mathbf{E} & \mathbf{V} & \mathbf{I} & \mathbf{S} & \mathbf{T} & \mathbf{A} & \text { ESTUDOS LINGUÍSTICOS - N. } 27 \text { - } 2014.1 \text { - Paula }\end{array}$ Barreto Silva e Ester Maria de F. Souza

escolas publicas brasileiras que apresenta uma sequência didática com atividades de leitura, escrita, reescrita de texto e do ensino da gramática própria para o gênero. A ideia é que o professor, realizando a sequência didática, aprenda alguns princípios de trabalho com a língua e passe a usá-los em outros projetos de escrita.

Sob a coordenação do Cenpec, a Olimpíada proporciona, para os professores e alunos inscritos, um mesmo referencial teórico-metodológico, que se constitui como um patamar comum inicial para a competição. Além disso, se constitui como um programa de formação em serviço que pretende inserir-se no cotidiano da escola como parte da programação regular de Língua Portuguesa e não como uma atividade extracurricular.

Rangel e Garcia (2012), ao tratarem da orientação teórico-metodológica da Olimpíada, observam que o programa se organiza em torno de três eixos básicos: a noção de gênero, as sequências didáticas e as teorias de Vigotsky relativas à aprendizagem. Para os autores, a Olimpíada se insere na "virada pragmática no ensino de língua materna" e, no contexto das políticas públicas, é um arranjo particular das perspectivas abertas pela virada pragmática, fazendo circular entre os docentes e orientadores educacionais, uma determinada concepção de linguagem e de ensino de língua materna, bem como uma metodologia particular de trabalho. Segundo os autores, a Olimpíada adota "uma forma bem delineada de ensino de língua portuguesa com foco na escrita":

Entre outras coisas, isso significa que as sequências didáticas propostas pelos cadernos não pretendem introduzir um parêntese mais ou menos breve nas atividades de sala de aula; procuram, antes, reorganizar o ensino de português, de forma a articular intimamente à produção textual as atividades consagradas aos eixos da leitura, da oralidade e da análise e reflexão sobre a língua e a linguagem (RANGEL; GARCIA, 2012, p. 15).

O concurso, atualmente tem as seguintes etapas: o texto vencedor da escola é postado no site e segue para as secretarias municipais de educação que fazem a primeira seleção dos textos da cidade vindos das escolas municipais e estaduais. Após essa etapa, os textos seguem para a etapa estadual. E, a partir dessa seleção, os alunos e professores participam de oficinas em quatro diferentes cidades do Brasil em que se reúnem os autores dos textos selecionados para cada gênero: Fortaleza, poema; São Paulo, artigo de opinião; Belo Horizonte, memórias; e Curitiba, crônica. Por três dias, alunos e professores vivenciam oficinas de reflexão para verificar se as produções são autênticas e para que, com o auxílio dos técnicos, o professor ajude o aluno a reescrever seu texto. 
$\begin{array}{llllllll}\mathbf{R} & \mathbf{E} & \boldsymbol{V} & \mathbf{I} & \mathbf{S} & \mathbf{T} & \mathbf{A} & \text { ESTUDOS LINGUístiCOS - N. } 27 \text { - } 2014.1 \text { - Paula }\end{array}$ Barreto Silva e Ester Maria de F. Souza

A educação linguística do aluno, mesmo não sendo só de responsabilidade do professor, deve decorrer do trabalho realizado em sala de aula: um trabalho que pressupõe cooperação entre as atividades do aluno e as sugestões do professor, além de ações didáticas integradas e coletivas na sala de aula e na sua inter-relação com a comunidade. $\mathrm{O}$ projeto tem diferentes agentes de execução: o MEC, a Fundação Itaú Social e o Cenpec, mas é um programa de ampla dimensão que mobiliza segmentos públicos, privados e sociedade civil na execução de suas ações.

Dentre os materiais disponibilizados como apoio pedagógico ao professor para o trabalho em sala de aula, selecionamos os Cadernos do Professor destinados ao apoio pedagógico para o ensino da produção textual dos quatro diferentes gêneros, buscando identificar índices linguístico-discursivos que deixem entrever a concepção de língua (gem) e educação linguística presente nos materiais disponibilizados para o ensino de língua portuguesa. Essa análise pretende identificar o modo como o programa direciona a reflexão e análise linguística para a produção de gêneros escritos na educação linguística formal voltada para os estudantes brasileiros inscritos no programa.

\section{Os Cadernos do professor e o trabalho de análise linguística na Olimpíada}

O caderno do professor se constitui como uma ferramenta chave para a realização do projeto. Esse material traz as orientações para o trabalho com a produção de textos em sala de aula, articulando teoria e prática, e contribui para a formação do professor em serviço. Os Cadernos do professor estão organizados em oficinas que apresentam uma sequência didática para o trabalho com os quatro gêneros textuais priorizados pelo programa: o caderno Poetas na escola (ALTENFELDER; ARMELIN, 2010) destina-se ao trabalho com o gênero Poema, nos $5^{\circ}$ e $6^{\circ}$ anos do Ensino Fundamental; o caderno Se bem me lembro (ClaRA et al., 2010) apresenta a proposta de trabalho com Memórias literárias, nos $7^{\circ}$ e $8^{\circ}$ anos do ensino fundamental; o caderno A ocasião faz o escritor (LAGINESTRA; PEREIRA, 2010) direciona o trabalho com a Crônica para o $9^{\circ}$ ano do ensino fundamental e $1^{\circ}$ ano do ensino médio; e o caderno Pontos de Vista (RANGel et al., 2010) apresenta a proposta para o trabalho com o artigo de opinião nos $2^{\circ}$ e $3^{\circ}$ anos do ensino médio. A proposta de uma educação linguística voltada para a promoção da cidadania é evidente no programa que visa à ampliação da competência comunicativa a partir do estudo e produção de gêneros textuais. 


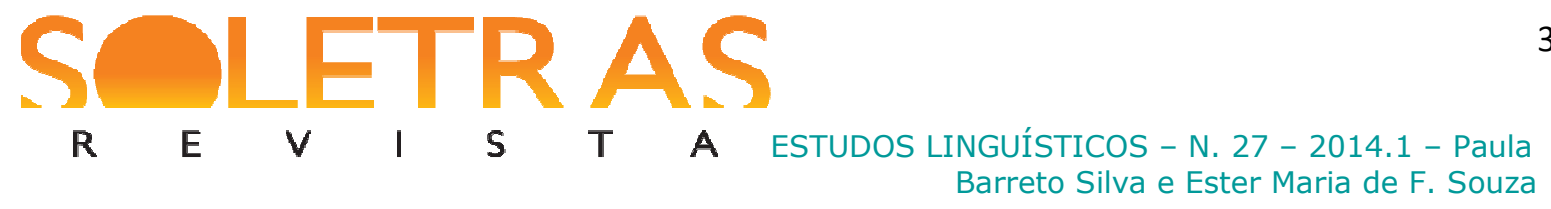

A Olimpíada não está em busca de talentos, mas tem o firme propósito de contribuir para a melhoria da escrita de todos. O importante é que os seus alunos cheguem ao final da sequência didática tendo aprendido a se comunicar com competência no gênero estudado. Isso contribuirá para que se tornem cidadãos mais bem preparados (RANGEL et al., 2010, p. 3).

A citação acima é comum aos quatro manuais disponibilizados pelo programa e dirigese ao professor explicando o que é a Olimpíada e quais são seus objetivos. No projeto, a capacidade de comunicação em determinado gênero é requisito para a formação cidadã do indivíduo, uma vez que o torna mais "bem preparado" para a vida em sociedade. A maioria das oficinas, propostas no manual do professor, prioriza o tratamento didático das características e conteúdos específicos do gênero estudado. No que diz repeito à análise linguística, nota-se que o projeto espera dos alunos um conhecimento linguístico formal prévio e que o professor apenas intervenha na atividade escrita dos alunos no sentido de melhorá-la e ampliá-la.

Para evidenciar como acontece o trabalho de análise linguística na proposta didática do programa, destacamos, após uma leitura prévia dos manuais do professor, alguns trechos da sequência didática que evidenciam o trabalho com a linguagem no programa e os critérios de avaliação das convenções de escrita para cada gênero. Os trechos referentes ao trabalho com análise linguística foram extraídos aleatoriamente dos manuais do professor a partir dos índices linguístico-discursivos que revelem as estratégias didáticas referentes à linguagem.

Os critérios de avaliação da adequação linguística e das convenções de escrita são apresentados no final de cada manual como parâmetros de análise dos textos produzidos no âmbito da Olimpíada. Os textos dos alunos participantes do concurso são avaliados de acordo com os seguintes critérios: tema "o lugar onde vivo", adequação ao gênero (adequação linguística e adequação discursiva), marcas de autoria e convenções de escrita. No quadro abaixo, destacamos, para os critérios de avaliação, apenas os itens descritos para "adequação linguística' e "convenções de escrita" referentes a cada gênero para, nos limites desse texto, promover reflexões sobre como o trabalho com análise linguística tem sido realizado por políticas públicas que se destinam à democratização dos usos da língua portuguesa através da produção escrita de textos em diferentes gêneros.

\begin{tabular}{|c|c|c|c|}
\hline $\begin{array}{c}\text { Gênero } \\
\text { textual }\end{array}$ & Trabalho com análise linguística & $\begin{array}{c}\text { Critérios de avaliação da } \\
\text { adequação linguística }\end{array}$ & $\begin{array}{c}\text { Critérios de } \\
\text { avaliação das } \\
\text { convenções de } \\
\text { escrita }\end{array}$ \\
\hline Poema & $-\begin{array}{l}\text { "O emprego da linguagem, pelo } \\
\text { poema, é feito de maneira diferente do }\end{array}$ & $\begin{array}{c}\text { Para a construção do } \\
\text { poema, o autor utiliza }\end{array}$ & $\begin{array}{l}\text { O poema segue as } \\
\text { convenções }\end{array}$ \\
\hline
\end{tabular}




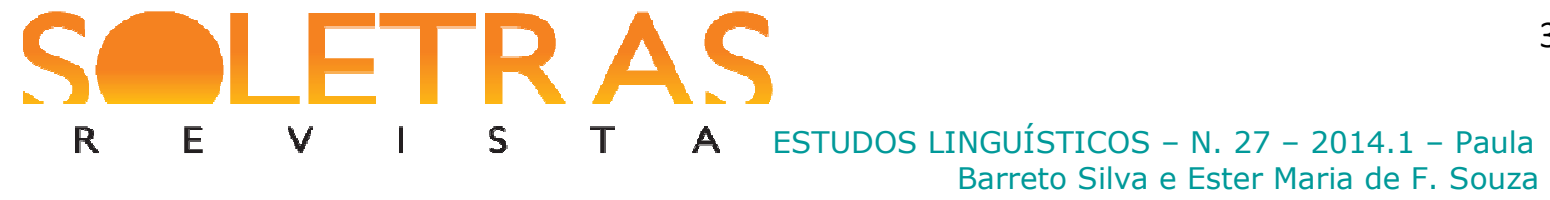

\begin{tabular}{|c|c|c|c|}
\hline & $\begin{array}{l}\text { que fazemos o dia a dia.” (p.121) } \\
\text { _ “Âs vezes, o poeta desrespeita } \\
\text { intencionalmente as regras } \\
\text { gramaticais: pontuação, concordância, } \\
\text { ortografia. Ele pode usar a transcrição } \\
\text { oral de uma palavra para mostrar o } \\
\text { jeito de falar do povo, por exemplo. Se } \\
\text { houver algum caso desses, seja } \\
\text { cuidadoso e verifique se o aluno está } \\
\text { usando adequadamente esse recurso ou } \\
\text { se apenas não sabem a grafia correta } \\
\text { de uma palavra ou a forma culta de } \\
\text { usar uma regra de concordância.” } \\
\text { (p.129) }\end{array}$ & 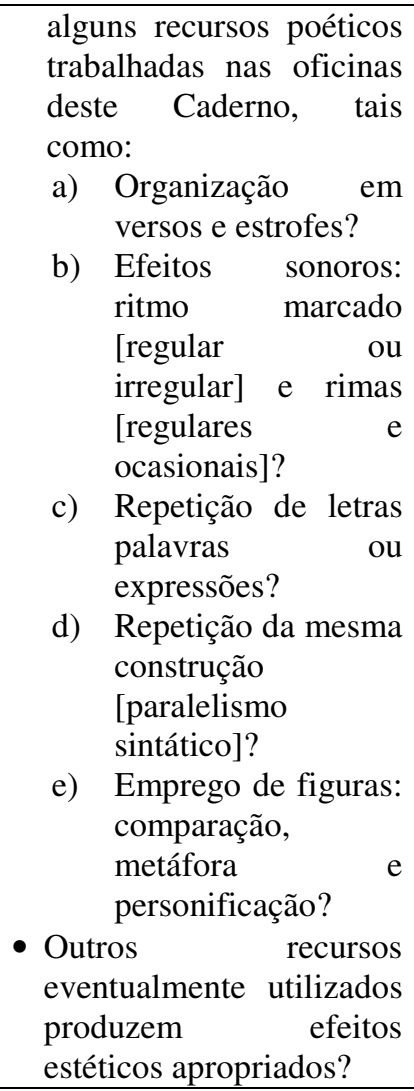 & 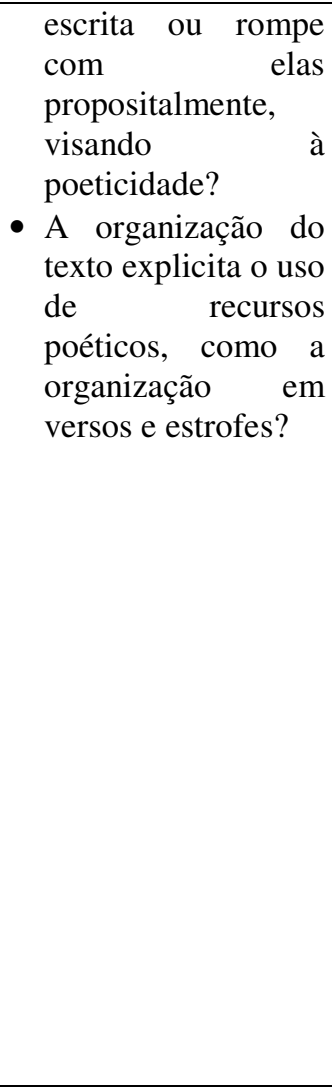 \\
\hline $\begin{array}{l}\text { Memórias } \\
\text { literárias }\end{array}$ & $\begin{array}{l}\text { - “O autor poderia trazer suas } \\
\text { impressões sobre o lugar, descrevendo } \\
\text { cores, cheiros, fazendo comparações } \\
\text { entre o passado e o presente. Poderia } \\
\text { buscar uma linguagem literária que } \\
\text { enredasse mais o leitor." (p.144) } \\
\text { - “O narrador usa a primeira pessoa para } \\
\text { contar as lembranças do entrevistado? } \\
\text { O que pode ser feito para que o texto } \\
\text { possa ser relatado em primeira } \\
\text { pessoa?” (p.147) } \\
\text { - "O texto traz palavras e expressões que } \\
\text { situam o leitor no tempo passado? Há } \\
\text { outros trechos em que é possível } \\
\text { acrescentá-las?" (p.147) } \\
\text { - "Há no texto trechos com marcas da } \\
\text { linguagem oral informal ("né”, "daí" } \\
\text { etc.), que devem ser substituídos por } \\
\text { expressões mais adequadas ao gênero } \\
\text { em questão?" (p.147) } \\
\text { - "Os verbos no pretérito perfeito e } \\
\text { imperfeito estão usados corretamente?' } \\
\text { (p.147) } \\
\text {-Há alguma palavra que não esteja } \\
\text { escrita corretamente? E a pontuação } \\
\text { está correta?" (p.147) }\end{array}$ & $\begin{array}{l}\text { - As memórias são } \\
\text { assumidas em primeira } \\
\text { pessoa? } \\
\text { - No caso de o autor } \\
\text { recorrer a outras vozes, } \\
\text { estão adequadamente } \\
\text { articuladas no texto? } \\
\text { - O uso dos tempos verbais } \\
\text { e dos indicadores de } \\
\text { espaço situa } \\
\text { adequadamente o leitor } \\
\text { em relação aos tempos e } \\
\text { espaços retratados no } \\
\text { texto? } \\
\text { - Os recursos de linguagem } \\
\text { são adequados ao caráter } \\
\text { literário das memórias? }\end{array}$ & $\begin{array}{l}\text { - O texto atende às } \\
\text { convenções de } \\
\text { escrita } \\
\text { (morfossintaxe, } \\
\text { ortografia, } \\
\text { acentuação, } \\
\text { pontuação)? } \\
\text { - Quando há } \\
\text { rompimento das } \\
\text { convenções de } \\
\text { escrita, isso ocorre } \\
\text { a serviço do } \\
\text { sentido do texto? }\end{array}$ \\
\hline Crônica & $\begin{array}{l}\text { - "Traz aspectos de oralidade para a } \\
\text { escrita: expressões de conversa } \\
\text { familiar e íntima, repetições e o } \\
\text { pronome "você"”. (p.78) }\end{array}$ & $\begin{array}{l}\text { - Os marcadores de tempo } \\
\text { e espaço contribuem para } \\
\text { caracterizar a situação } \\
\text { tratada? }\end{array}$ & $\begin{array}{l}\text { - O texto atende às } \\
\text { convenções da } \\
\text { escrita } \\
\text { (morfossintaxe, } \\
\text { ortografia, }\end{array}$ \\
\hline
\end{tabular}




\begin{tabular}{|c|c|c|c|}
\hline & 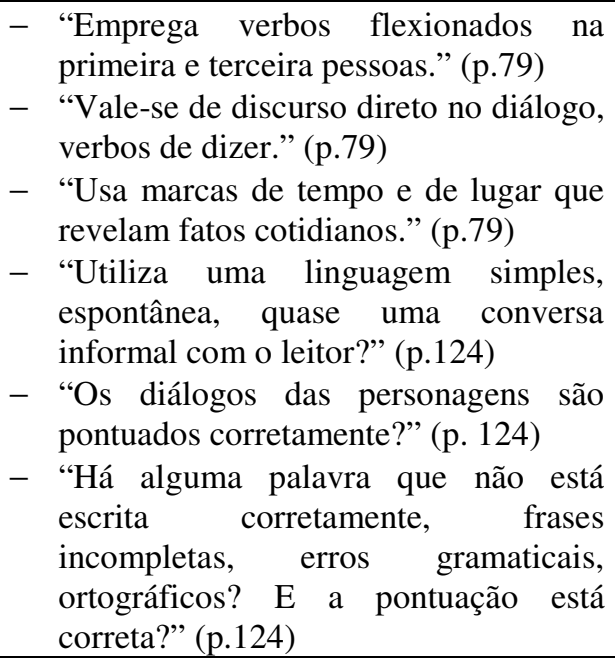 & $\begin{array}{l}\text { - Os articuladores textuais } \\
\text { são apropriados ao tipo } \\
\text { de crônica escolhido pelo } \\
\text { autor? } \\
\text { - Os recursos de linguagem } \\
\text { estão adequados ao tom } \\
\text { visador (irônico, } \\
\text { humorístico, lírico, } \\
\text { crítico)? }\end{array}$ & $\begin{array}{l}\text { acentuação, } \\
\text { pontuação)? } \\
\text { - Quando } \\
\text { rompimento das } \\
\text { convenções da } \\
\text { escrita, isso ocorre } \\
\text { a serviço do } \\
\text { sentido do texto? }\end{array}$ \\
\hline $\begin{array}{l}\text { Artigo de } \\
\text { opinião }\end{array}$ & $\begin{array}{l}\text { - "Esse parágrafo inicial poderia ser } \\
\text { melhorado se o aluno usasse uma } \\
\text { linguagem mais próxima da } \\
\text { jornalística, ou seja, menos coloquial } \\
\text { [...]" (p.137) } \\
\text { - "Introduziu sua opinião com } \\
\text { expressões como 'penso que', 'na } \\
\text { minha opinião'?" (p. 147) } \\
\text { - “Utilizou expressões que introduzem } \\
\text { argumentos, como 'pois', 'porque'?" } \\
\text { (p.147) } \\
\text { - "Verificou se a pontuação está } \\
\text { correta?" (p.147) } \\
\text { - "Corrigiu os erros de ortografia?" } \\
\text { (p.147) } \\
\text { "Substituiu palavras repetidas e } \\
\text { eliminou as desnecessárias?” (p.147) }\end{array}$ & $\begin{array}{l}\text { - O texto deixa } \\
\text { transparecer claramente o } \\
\text { ponto de partida (os } \\
\text { dados) e a conclusão (ou } \\
\text { tese) a que se pretende } \\
\text { chegar? } \\
\text { - As justificativas (ou } \\
\text { argumentos) sustentam } \\
\text { consistentemente a } \\
\text { conclusão (ou tese) do } \\
\text { autor? } \\
\text { - Estratégias } \\
\text { argumentativas como a } \\
\text { refutação e a utilização } \\
\text { de diferentes vozes estão } \\
\text { presentes no artigo? } \\
\text { - O texto é coeso? Os } \\
\text { elementos de articulação } \\
\text { são adequadamente } \\
\text { utilizados? }\end{array}$ & $\begin{array}{l}\text { - } \mathrm{O} \text { texto atende às } \\
\text { convenções da } \\
\text { escrita } \\
\text { (morfossintaxe, } \\
\text { ortografia, } \\
\text { acentuação, } \\
\text { pontuação)? }\end{array}$ \\
\hline
\end{tabular}

Verifica-se que o trabalho com análise linguística empreendido no contexto da Olimpíada direciona-se por aspectos relacionados à ordem do texto, ao nível de linguagem, aos aspectos gramaticais, tais como a sintaxe, morfologia, fonologia, ortografia, pontuação, concordância. Determinados recursos linguísticos têm o uso diretamente relacionado ao gênero textual, como o emprego de figuras de linguagem nos poemas e o uso de elementos de articulação nos artigos de opinião. Outros são elementos comuns a qualquer texto, como a ortografia e a pontuação, por exemplo. Em alguns casos, como na ortografia e convenções de escrita, exige-se o conhecimento da norma para todos os gêneros, mas permite-se o rompimento proposital a serviço dos efeitos de sentido.

As normas de comportamento linguístico priorizadas pela Olimpíada são aquelas relacionadas à produção do gênero textual trabalhado, acredita-se que a aquisição de padrões 


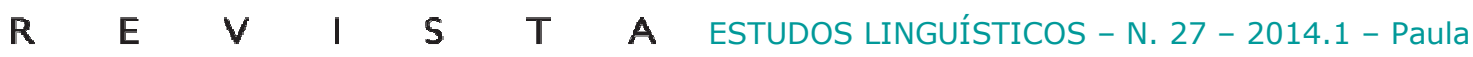
Barreto Silva e Ester Maria de F. Souza

linguísticos de determinado gênero permite a sua aplicação a gêneros de uma mesma esfera, possibilitando que, informalmente, o indivíduo vá ampliando o seu desempenho comunicativo.

Não há dúvida de que o papel do professor é essencial para o sucesso do projeto, pois a ele cabe identificar as potencialidades de seus alunos e escolher as oficinas e sequências necessárias para que eles ampliem o domínio linguístico-discursivo do gênero em foco, diferenciando as atividades a partir da necessidade individual de determinados alunos ou grupos de alunos, por exemplo, ou mesmo acrescentando sequências não previstas no modelo didático proposto, mas necessárias ao desempenho de seus alunos. $\mathrm{O}$ trabalho do professor começa a partir de atividades coletivas, mas, no programa, ele deve também intervir diretamente na produção textual do aluno como interlocutor, mediador e coautor. $\mathrm{O}$ aluno escreve junto com seus pares e com o professor, enquanto amplia sua competência comunicativa, para, nas suas atividades cotidianas, estar apto para poder atuar sozinho.

\section{Conclusões}

A análise dos materiais disponibilizados pela Olimpíada de Língua Portuguesa Escrevendo o Futuro, mais especificamente os Caderno do professor, revela que o tratamento didático dos gêneros explorados no programa, bem como os pressupostos teóricometodológicos, ancoram-se na concepção sociointeracionista da linguagem com todas as suas implicações para o ensino de língua materna, dado extraído não somente do manual do professor como também das análises de pesquisadores vinculados ao programa. Verifica-se ainda que as normas de comportamento linguístico priorizadas na Olimpíada relacionam-se intimamente aos padrões linguístico-discursivos do gênero em foco.

O projeto tem objetivos bem definidos na tentativa de atender a atual demanda para o ensino de língua no Brasil e a melhoria da produção escrita de estudantes das escolas públicas. O programa dispõe de processos formativos tanto para o professor, quando propõe o domínio dos princípios do interacionismo sócio discursivo para organização do trabalho escolar, como para o aluno, ao indicar os módulos de refacção textual. Com esses objetivos, busca inserir-se no programa curricular comum para o ensino de língua portuguesa no território brasileiro. A Olimpíada, no percurso de dados que temos organizado para desenvolver estudos, tende a se caracterizar, portanto, como um veículo de planificação do 


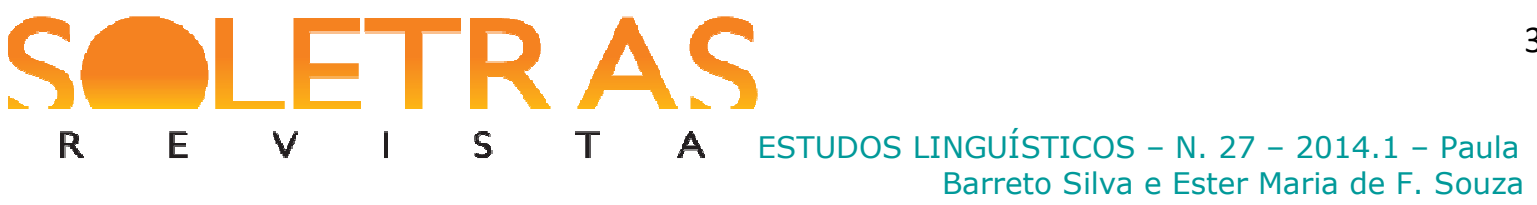

ensino de língua no país e como uma política pública de ensino de língua materna que direciona a educação linguística formal.

\section{Referências bibliográficas:}

ALTENFELDER, A.; ARMELIN, M. Poetas na escola. São Paulo: Cenpec; Brasília: MEC, 2010 (Coleção Olimpíada).

CLARA, R. et al. Se bem me lembro... São Paulo: CENPEC; Brasília: MEC, 2010 (Coleção Olimpíada).

DOLZ, J. et al. Sequências didáticas para o oral e a escrita: apresentação de um procedimento. In: SCHNEUWLY, B.; DOLZ, J. Gêneros orais e escritos na escola. 2. ed. Campinas, SP: Mercado de Letras, 2010. p. 81-108.

LAGINESTRA, M.; PEREIRA, M. A ocasião faz o escritor. São Paulo: Cenpec: Brasília: MEC, 2010 (Coleção Olimpíada).

MENDONÇA, M. Análise linguística no ensino médio:um novo olhar, um outro objeto. In: BUNZEN. C.; MENDONÇA, M. (Org.) Português no ensino médio e formação do professor. São Paulo: Parábola Editorial, 2006. p. 109-226.

PESSOA, M. S. Concepções de linguagem e políticas linguístico-culturais: aproximações e/ou afastamentos na Educação Linguística. In: ANÇÃ, M. H.; FERREIRA, T. (Orgs.). Actas do Seminário "Língua Portuguesa e Integração", Universidade de Aveiro. Portugal, 2007. www.oi.acidi.gov.pt/docs/SeminarioLPIntegracao/8_Maria_Socorro_Pessoa.pdf. Acesso em: 13 out. 2012.

RANGEL, E. O. et al. Pontos de Vista. São Paulo: Cenpec; Brasília: MEC, 2010 (Coleção Olimpíada).

RANGEL, E. O.; GARCIA, A. L. M. A Olimpíada de Língua Portuguesa e os caminhos da escrita na escola pública: uma introdução. Cadernos Cenpec, v. 2, n. 1, p. 11-22, jul. 2012.

SANTOS, I. B. A.; OLIVEIRA, M. S. Políticas públicas na educação de jovens e adultos: projetos de letramento, participação e mudança social. EJA em debate, v. 1, n. 1, p. 39-56, nov. 2012.

SCHNEUWLY, B.; DOLZ, J. Os gêneros escolares - das práticas de linguagem aos objetos de ensino. In: _. Gêneros orais e escritos na escola. 2. ed. Campinas, SP: Mercado de Letras, 2010, p. 61-78.

SOUZA, E. M. F. A aula de português como instância de produção e circulação de conhecimentos linguísticos e não linguísticos. In: SOUZA, E. M. F.; CRUZ, G. F. (Orgs.) Linguagem e ensino: elementos para reflexão nas aulas de língua inglesa e língua portuguesa. Vitória da Conquista, BA: Edições UESB, 2009, p. 97-112. 


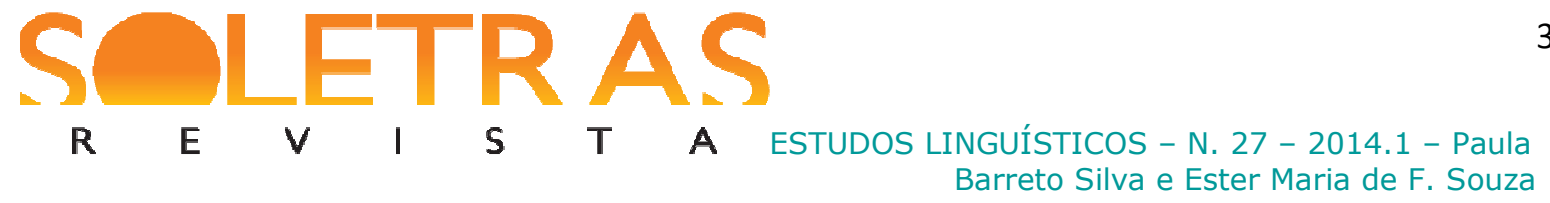

VASCONCELOS, M. L. M. C. A educação lingüística e a formação de professores. Cadernos de Letras da UFF. Dossiê: Diálogos internacionais, n. 38, p. 205-215, 2009.

\title{
Linguistic education: the teaching of the Portuguese language in the project Escrevendo o Futuro
}

\begin{abstract}
Teaching Portuguese has been touted in Brazilian linguistic policies as a right to be extended and guaranteed to all citizens, both within the teacher training for the domain knowledge of the language and didactic teaching, as linguistic education for learners. Official indexes of evaluation for basic education reveal us the necessity of being attentive to the complexity of education in mother tongue and drive us on promoting reflection on actions and public policies of Portuguese language teaching developed in the country, in order to observe whether they seek to meet social demands. We intend, then, in this work, to extract from materials of Olimpíada de Língua Portuguesa - OLP, conceptions of language teaching to the country, based on a survey of linguistic-discursive indexes about reflection on and linguistic analysis present in Notebooks Teacher. The program promotes among public school students, biannual contests for production of written texts in four genres and it is guided by a methodology organized on didactic sequences. Results show that the OLP is characterized as an education policy that prioritizes the rules of linguistic behavior related to written genres and their production conditions and tends to be characterized as a vehicle for the standardize of language teaching in the country.
\end{abstract}

Key words: Linguistic education. Textual genres. Portuguese. Written production.

Recebido em: 05 de agosto de 2013.

Aprovado em: 12 de novembro de 2013. 